\title{
Buccal localization of Crohn's disease with long-term infliximab therapy: a case report
}

\author{
Carolina Ciacci ${ }^{1 *}$, Cristina Bucci ${ }^{1}$, Fabiana Zingone ${ }^{1}$, Paola lovino ${ }^{1}$ and Massimo Amato $^{2}$
}

\begin{abstract}
Introduction: Cheilitis granulomatosa causes persistent idiopathic lip swelling and ulceration and it can sometimes be recognized as a unique or early manifestation of Crohn's disease. Spontaneous remission is rare and with the lack of controlled trials, different therapeutic approaches have been used. Some cases have been treated with an exclusion diet in the attempt to rule out diet allergens, while the most popular treatments include antibiotics such as tetracycline and clofazimine tranilast, benzocaine topical or intralesional steroids, and cheiloplasty, with different outcomes.
\end{abstract}

Case presentation: We describe the case of a 23-year-old Caucasian man, primarily diagnosed with cheilitis granulomatosa for a severe lower lip swelling, and then with Crohn's disease of the terminal ileum and anus. Treatment of Crohn's disease with an anti-tumor necrosis factor alpha agent (infliximab) successfully induced remission of both the gastrointestinal disease and the oral lesion.

Conclusions: Our recommendation is that physicians should be able to recognize cheilitis granulomatosa as a possible marker of a more complex systemic disease and proceed first with an accurate physical examination, and further suggest investigations of the bowel. In cases of Crohn's disease, a therapy with biological agents can be successful.

Keywords: Cheilitis granulomatosa, Crohn's disease, Mouth, Infliximab, Treatment

\section{Introduction}

Cheilitis granulomatosa (CG) causes persistent idiopathic lip swelling and ulceration and it is included in the orofacial granulomatosis group [1]. The pathogenesis of this disease is still unknown. Spontaneous remission is rare, and with the lack of controlled trials, different therapeutic approaches have been used with regard to the primary etiology of the CG and the personal experience of physicians. CG can occur by itself, can be due to dietary allergens, and also be a feature of MelkerssonRosenthal syndrome [1]. It can sometimes be recognized as a unique or early manifestation of Crohn's disease, a disease that may involve the whole gastrointestinal tract, including the mouth and the perianal area [2], although this is considered rare [3]. Here we describe an unusual

\footnotetext{
* Correspondence: cciacci@unisa.it

${ }^{1}$ Gastroenterology Unit, Department of Medicine and Surgery, University of Salerno, Baronissi Campus, via S. Allende, 84081 Baronissi, Salerno, Italy Full list of author information is available at the end of the article
}

case of a patient with ileal and perianal Crohn's disease associated with CG, successfully treated with infliximab.

\section{Case presentation}

We present the case of a 23-year old-Caucasian man who was initially diagnosed with CG of the lower lip in 2009. He underwent a number of first topic and then systemic treatments with antibiotics and steroids with little or no improvement in the lower lip. In the same period, he underwent psychotherapy for low self-esteem and bad school performance due to his mouth appearance. In January 2011, to confirm the diagnosis of CG, a lower lip biopsy was taken. The pathologist described normal keratinizing squamous epithelium overlying inflammatory tissue with non-caseating granulomatous inflammation in the deeper subcutaneous and parafollicular tissues, consistent with cheilitis granulomatosa. His ZiehlNeelsen, silver, periodic acid-Schiff, and Warthin-Starry staining results were negative for acid-fast (Mycobacteria and Actinomyces, specifically), fungal, and spirochetal organisms. In February 2011, he complained of pain during 


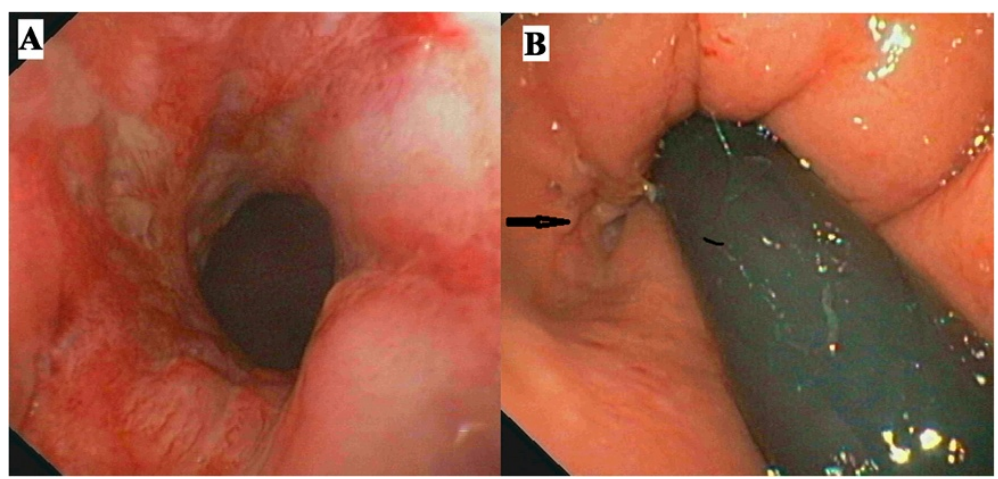

Figure 1 Colonoscopy. Panel A shows the rectal inflamed mucosa and panel B (arrow) the opening of an anal fistula.

defecation and underwent an evaluation. His rectal examination showed a diffuse, severe, perianal disease characterized by perianal fissures, fistulae, and abscesses. After an in-depth interview, he revealed that in 2009 he had an over-the-counter topic preparation prescribed by his general practitioner (GP) for anal fissuration and had had a moderate discomfort at evacuation since then. The severity of the anal disease and the previous diagnosis of CG alerted us to investigate the possibility of Crohn's disease by colonoscopy. His endoscopy examination showed a diffuse aphthosis in a very limited region of the rectal ampulla and terminal ileum, and ileal and rectal biopsies were suggestive of a diffuse granulomatous inflammation, compatible with Crohn's disease (Figure 1). Intestinal ultrasound and magnetic resonance of the intestine confirmed the diagnosis of terminal ileal and perianal Crohn's disease. After surgical drainage of perianal disease, he was started on infliximab (given as intravenous infusions at dosage of $5 \mathrm{mg} / \mathrm{kg}$ at 0,2 and 6 weeks, and at maintenance schedule of $5 \mathrm{mg} / \mathrm{kg}$ every 8 weeks). He also underwent regular follow-ups that included an endoscopy, histology, and intestinal ultrasound, as per our protocol.

Since the beginning of anti-tumor necrosis factor alpha (TNFo) therapy in 2011, we observed a slow decrease of the swelling of his lips as shown in Figure 2, together with a healing of the terminal ileum assessed by endoscopies and magnetic resonance imaging examinations. His perianal lesions disappeared, although a diffuse fibrosis of the anal canal, requiring anal dilations, is still present. No adverse events were noted during the three-year therapy. Notably, the psychological impairment improved and recently he has entered into a nursing school program.

\section{Discussion}

Intestinal Crohn's disease is accompanied by a number of disease-specific oral lesions, such as swelling of the lips, buccal mucosal swelling or cobble stoning, mucogingivitis, deep linear ulceration, perioral erythema with

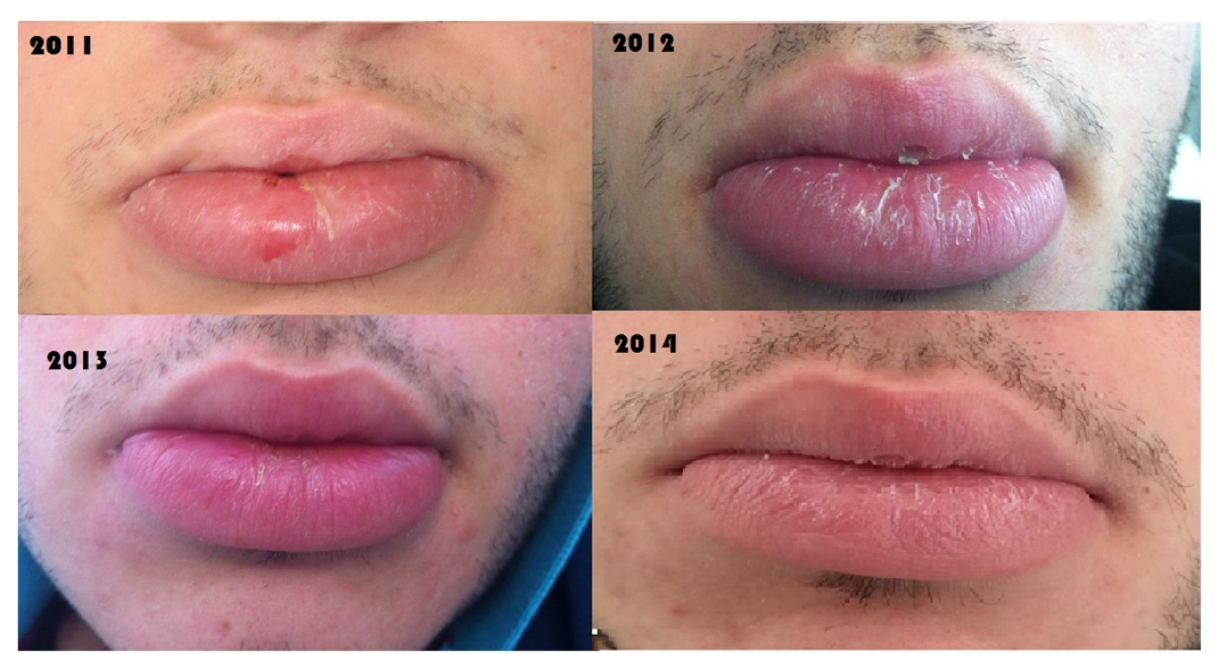

Figure 2 Modification of lip swelling. The figure shows gradual changes in lip swelling in our patient since the beginning of infliximab therapy. 
Table 1 Review of the most relevant literature on treatment of cheilitis granulomatosa

\begin{tabular}{|c|c|c|c|c|}
\hline Author, year of publication & Diagnosis & $\begin{array}{l}\text { Number of } \\
\text { cases }\end{array}$ & Therapy & Results \\
\hline Martinez Martinez et al. 2012 [14] & CG & 6 & $\begin{array}{l}\text { TCA sulfone, oral steroids, tetracyclines, } \\
\text { hydroxychloroquine, amoxicillin-clavulanic acid }\end{array}$ & $\begin{array}{l}\text { Moderate } \\
\text { (1 recurrence) }\end{array}$ \\
\hline $\begin{array}{l}\text { Ruiz Villaverde and Sanchez, } \\
2012 \text { [15] }\end{array}$ & CG & 1 & Adalimumab & Good \\
\hline Álvarez-Garrido et al., 2011 [16] & $C D+C G$ & 1 & Remicade & Good \\
\hline Macaigne et al., 2011 [17] & $C D+C G$ & 1 & Remicade & Good \\
\hline Sasaki et al., 2011 [18] & CG & 1 & Dental treatment & $\begin{array}{l}\text { Markedly } \\
\text { improved }\end{array}$ \\
\hline \multirow[t]{2}{*}{ Kawakami et al., 2008 [19] } & CG & 1 & $\begin{array}{l}\text { Corticosteroid ointment } \\
\text { and oral tranilast }\end{array}$ & None \\
\hline & & & Paradentitis treatment & Good \\
\hline Mignogna et al., 2008 [9] & $C D$ & 1 & TCA & Good \\
\hline Inui, 2008 [20] & CG & 1 & Roxithromycin & Good \\
\hline \multirow[t]{14}{*}{ Ratzinger et al., 2007 [21] } & CG & 1 & Methylprednisolone, Clofazimine & Moderate \\
\hline & $U G+C D$ & 1 & None & None \\
\hline & MRS & 1 & Clofazimine & Good \\
\hline & CG & 1 & Clofazimine & Good \\
\hline & CG & 1 & Clofazimine & None \\
\hline & CG & 1 & Clofazimine & Good \\
\hline & MRS & 1 & Clofazimine & Good \\
\hline & BG & 1 & Clofazimine & Good \\
\hline & $P G$ & 1 & Clofazimine & Good \\
\hline & $C G+C D$ & 1 & Methylprednisolone, Azathioprine & Good \\
\hline & MRS & 1 & Methylprednisolone, Infliximab & Good \\
\hline & CG & 1 & None & None \\
\hline & $C G+C D$ & 1 & Methylprednisolone, Azathioprine, Infliximab & Good \\
\hline & $P G+C D$ & 1 & Clofazimine & Good \\
\hline Tonkovic-Capin, 2006 [22] & $\mathrm{CD}+\mathrm{CG}$ & 1 & Methotrexate & Good \\
\hline \multirow[t]{2}{*}{ Kruse-Losler et al., 2005 [23] } & MRS & 3 & Cheiloplasty & Good \\
\hline & CG & 4 & & \\
\hline \multirow[t]{2}{*}{ Bogenrieder et al., 2003 [24] } & $C G+C D$ & 1 & Mesalazine, & Good \\
\hline & & & prednisolone per os & \\
\hline Hegarty et al., 2003 [25] & $C D+C G$ & 5 & Thalidomide & Good \\
\hline \multirow[t]{2}{*}{ Sciubba et al., 2003 [26] } & MRS + oral granulomatosis & 7 & TCA chlorhexidine, & Moderate \\
\hline & $C D+C G$ & 6 & TCA, systemic sulfasalazine/steroids & Moderate \\
\hline \multirow[t]{2}{*}{ Kolokotronis et al., 1997 [27] } & CG & 5 & In 3 intralesional corticosteroids & Good \\
\hline & & & In 2 oral corticosteroids [2] & \\
\hline Ochonisky et al., 1992 [28] & $C D$ & 1 & Hydroxychloroquine & Good \\
\hline Krutchkoff and James, 1978 [29] & CG & 1 & TCA +cheiloplasty & Good \\
\hline
\end{tabular}

CG, cheilitis granulomatosa; CD, Crohn's disease; TCA, triamcinolone acetate intralesional injections; UG, uranitis granulomatosa; PG, pareitis granulomatosa; $\mathrm{BG}$, blepharitis granulomatosa.

Results: none =no remission, moderate =partial remission, good =complete remission. MRS: Melkersson-Rosenthal syndrome. 
scaling, recurrent buccal abscesses, and angular cheilitis and mucosal tags [4-6]. These lesions are recurrent and generally improve with immunosuppressant therapy in about $70 \%$ of cases [7-10].

It is likely that in our case report Crohn's disease was already present in 2009 when he was first treated for anal fissure. Concomitantly, the swelling of his lip appeared and diagnosis of CG was made, as described in previous reports [11]. At that time, full attention was paid to the appearance of the mouth and his anal disease was underestimated. Our patient claimed that the CG, more than the anal manifestation, caused the psychological problems and subsequent psychotherapy, as already shown [12]. In our case report, all the Crohn's disease localizations were successfully treated with infliximab. Also, the psychological impairment was overcome with the healing of his mouth lesion.

Spontaneous remission is rare, and some cases have been treated with an exclusion diet [13]. Table 1 summarizes the most popular treatments of CG including antibiotics such as tetracycline and clofazimine tranilast, benzocaine topical or intralesional steroids, and cheiloplasty, with different outcomes in relation to the followup period. Obviously with the lack of controlled trials, different therapeutic approaches have been used with regard to the primary etiology of the CG and the personal experience of physicians.

Orofacial granulomatosis such as CG can be a therapeutic challenge for gastroenterologists and other physicians. When CG is accompanied by a major immune-mediated disease, such as inflammatory bowel disease or arthritis, it is reasonable to consider an anti-TNF $\alpha$ therapy that will control the major disease and improve and/or heal CG. Also, in the case of oral Crohn's disease, cheiloplasty has not been used so far for fear of surgery complications.

\section{Conclusions}

Orofacial granulomatosis such as CG can be a therapeutic challenge for gastroenterologists and other physicians When CG is accompanied by a major immune-mediated disease, such as inflammatory bowel disease or arthritis, it is reasonable to consider an anti-TNF therapy that will control the major disease and improve and/or heal CG. Also, in the case of oral Crohn's disease, cheiloplasty has not been used so far for fear of surgery complications.

The patients may indeed psychically suffer from the appearance of their lips, such as in our case report, and request the maximum available therapy. Our experience has demonstrated that infliximab is a useful therapeutic tool for CG associated with Crohn's disease.

Systematic assessment of the oral cavity will detect the presence of lip swelling, ulcers of the buccal mucosa and sulci, commissures, gingiva, tongue, floor of the mouth, and hard and soft palate and lymph nodes. If oral lesions are present, the next step is to refer the patient to the dentist to photograph, and if needed, take a biopsy of the lesion for follow-up treatment.

Our recommendation is that not only the gastroenterologist but also GPs, dentists and dermatologists, should be able to recognize these lesions as possible markers of a more complex systemic disease and proceed first with accurate physical examination, and further suggest investigation of the bowel.

\section{Consent}

Written informed consent was obtained from the patient for publication of this case report and any accompanying images. A copy of the written consent is available for review by the Editor-in-Chief of this journal.

\section{Abbreviations}

anti-TNFa: Antibodies against tumor necrosis factor alfa; CG: Cheilitis granulomatosa; GP: General practitioner.

\section{Competing interests}

The authors declare that they have no competing interests.

\section{Authors' contributions}

CC: conception and design and interpretation of data. CB, FZ: drafting the article and interpretation of data. PI, MA: follow-up of patient, participated in drafting the article and revising it critically. All authors read and approved the final manuscript.

\section{Author details}

${ }^{1}$ Gastroenterology Unit, Department of Medicine and Surgery, University of Salerno, Baronissi Campus, via S. Allende, 84081 Baronissi, Salerno, Italy.

${ }^{2}$ Dentistry Unit, Department of Medicine and Surgery, University of Salerno, Baronissi Campus, via S. Allende, 84081 Baronissi, Salerno, Italy.

Received: 26 June 2014 Accepted: 23 September 2014 Published: 30 November 2014

\section{References}

1. Tilakaratne WM, Freysdottir J, Fortune F: Orofacial granulomatosis: review on aetiology and pathogenesis. J Oral Pathol Med 2008, 37:191-195.

2. Ahmad I, Owens D: Granulomatous cheilitis and Crohn's disease. Can J Gastroenterol 2001, 15:273-275.

3. Dupuy A, Cosnes J, Revuz J, Delchier JC, Gendre JP, Cosnes A: Oral Crohn disease: clinical characteristics and long-term follow-up of 9 cases. Arch Dermatol 1999, 135:439-442.

4. Halme L, Meurman JH, Laine $P$, von Smitten $K$, Syrjanen S, Lindqvist C, Strand-Pettinen I: Oral findings in patients with active or inactive Crohn's disease. Oral Surg Oral Med Oral Pathol 1993, 76:175-181.

5. Issa MA: Crohn's disease of the mouth. A case report. Br Dent J 1971, 130:247-248.

6. Plauth M, Jenss H, Meyle J: Oral manifestations of Crohn's disease. An analysis of 79 cases. J Clin Gastroenterol 1991, 13:29-37.

7. Barry O, Barry J, Langan S, Murphy M, Fitzgibbon J, Lyons JF: Treatment of granulomatous cheilitis with infliximab. Arch Dermatol 2005, 141:1080-1082.

8. Gaya DR, Aitken S, Fennell J, Satsangi J, Shand AG: Anti-TNF-alpha therapy for orofacial granulomatosis: proceed with caution. Gut 2006, 55:1524-1525.

9. Mignogna MD, Fortuna G, Leuci S, Amato M: Oral Crohn's disease: a favorable clinical response with delayed-release triamcinolone acetonide intralesional injections. Am J Gastroenterol 2008, 103:2954-2955.

10. Peitsch WK, Kemmler N, Goerdt S, Goebeler M: Infliximab: a novel treatment option for refractory orofacial granulomatosis. Acta Derm Venereol 2007, 87:265-266.

11. Ghandour K, Issa M: Oral Crohn's disease with late intestinal manifestations. Oral Surg Oral Med Oral Pathol 1991, 72:565-567. 
12. Adamo D, Ruoppo E, Leuci S, Aria M, Amato M, Mignogna MD: Sleep disturbances, anxiety and depression in patients with oral lichen planus: a case-control study. J Eur Acad Dermatol Venereol 2014. doi:10.1111/ jdv. 12525.

13. Reed BE, Barrett AP, Katelaris C, Bilous M: Orofacial sensitivity reactions and the role of dietary components. Case reports. Aust Dent J 1993, 38:287-291.

14. Martinez Martinez ML, Azana-Defez JM, Perez-Garcia LJ, Lopez-Villaescusa MT, Rodriguez Vazquez M, Faura BC: Granulomatous cheilitis: a report of 6 cases and a review of the literature. Actas Dermosifiliogr 2012, 103:718-724.

15. Ruiz Villaverde R, Sanchez CD: Successful treatment of granulomatous cheilitis with adalimumab. Int J Dermatol 2012, 51:118-120.

16. Alvarez-Garrido H, Pericet-Fernandez L, Martinez-Garcia G, Tejerina-Garcia JA, Peral-Martinez I, Miranda-Romero A: Crohn's disease and cheilitis granulomatosa: role of silicone fillers. J Am Acad Dermatol 2011, 65:239-241.

17. Macaigne G, Harnois F, Boivin JF, Dikov D, Ridoux G, Cheaib S, Chayette C: Crohn's disease revealed by a cheilitis granulomatosa with favorable evolution by perfusions of infliximab: report of a case and review of the literature. Clin Res Hepatol Gastroenterol 2011, 35:147-149.

18. Sasaki R, Suzuki K, Hayashi T, Inasaka H, Matsunaga K: Improvement of cheilitis granulomatosa after dental treatment. Case Rep Dermatol 2011, 3:151-154.

19. Kawakami T, Fukai K, Sowa J, Ishii M, Teramae H, Kanazawa K: Case of cheilitis granulomatosa associated with apical periodontitis. J Dermatol 2008, 35:115-119.

20. Inui S, Itami S, Katayama I: Granulomatous cheilitis successfully treated with roxithromycin. J Dermatol 2008, 35:244-245.

21. Ratzinger $G$, Sepp $N$, Vogetseder $W$, Tilg H: Cheilitis granulomatosa and Melkersson-Rosenthal syndrome: evaluation of gastrointestinal involvement and therapeutic regimens in a series of 14 patients. J Eur Acad Dermatol Venereol 2007, 21:1065-1070.

22. Tonkovic-Capin V, Galbraith SS, Rogers RS III, Binion DG, Yancey K: Cutaneous Crohn's disease mimicking Melkersson-Rosenthal syndrome: treatment with methotrexate. J Eur Acad Dermatol Venereol 2006, 20(4):449-452.

23. Kruse-Losler B, Presser D, Metze D, Joos U: Surgical treatment of persistent macrocheilia in patients with Melkersson-Rosenthal syndrome and cheilitis granulomatosa. Arch Dermatol 2005, 141:1085-1091.

24. Bogenrieder T, Rogler G, Vogt T, Landthaler M, Stolz W: Orofacial granulomatosis as the initial presentation of Crohn's disease in an adolescent. Dermatology 2003, 206:273-278.

25. Hegarty A, Hodgson T, Porter S: Thalidomide for the treatment of recalcitrant oral Crohn's disease and orofacial granulomatosis. Oral Surg Oral Med Oral Pathol Oral Radiol Endod 2003, 95:576-585.

26. Sciubba JJ, Said-Al-Naief N: Orofacial granulomatosis: presentation pathology and management of 13 cases. J Oral Pathol Med 2003, 32:576-585.

27. Kolokotronis A, Antoniades D, Trigonidis G, Papanagiotou P: Granulomatous cheilitis: a study of six cases. Oral Dis 1997, 3:188-192.

28. Ochonisky S, Bonvalet D, Caron C, Kornhauser R, Vignon-Pennamen MD, Dubertret L: Granulomatous cheilitis with cutaneous extension in Crohn disease. Regression with hydroxychloroquine. Ann Dermatol Venereol 1992, 119:844-846.

29. Krutchkoff $D$, James $R$ : Cheilitis granulomatosa. Successful treatment with combined local triamcinolone injections and surgery. Arch Dermatol 1978, 114:1203-1206.

doi:10.1186/1752-1947-8-397

Cite this article as: Ciacci et al:: Buccal localization of Crohn's disease with long-term infliximab therapy: a case report. Journal of Medical Case Reports 2014 8:397.

\section{Submit your next manuscript to BioMed Central and take full advantage of:}

- Convenient online submission

- Thorough peer review

- No space constraints or color figure charges

- Immediate publication on acceptance

- Inclusion in PubMed, CAS, Scopus and Google Scholar

- Research which is freely available for redistribution

Submit your manuscript at www.biomedcentral.com/submit 